\title{
Basophil activation test: mechanisms and considerations for use in clinical trials and clinical practice
}

\author{
Alexandra Santos ${ }^{1,1}$, Oral Alpan², and Hans Jürgen Hoffmann³ \\ ${ }^{1}$ King's College London \\ ${ }^{2} \mathrm{O} \& \mathrm{O}$ ALPAN \\ ${ }^{3}$ Aarhus University Hospital
}

July 16, 2020

\begin{abstract}
The basophil activation test (BAT) is a functional assay that measures the degree of degranulation following stimulation with allergen or controls by flow cytometry and is directly correlated with histamine release. From the bell-shaped curve resulting from BAT in allergic patients, basophil reactivity (given by \%CD63+ basophils) and basophil sensitivity (given by EC50 or similar) are the main outcomes of the test. BAT takes into account all characteristics of IgE and allergen and thus can be more specific than sensitization tests in the diagnosis of allergic disease. BAT reduces the need for in vivo procedures, such as intradermal tests and allergen challenges, which can cause allergic reactions of unpredictable severity. As it closely reflects the patients' phenotype, it can potentially be used to monitor the natural resolution of food allergies and to predict and monitor clinical response to immunomodulatory treatments, such as allergen-specific immunotherapy and biologicals. Clinical application of BAT requires analytical validation, clinical validation, standardization of procedures and quality assurance to ensure reproducibility and reliability of results. Currently, efforts are ongoing to establish a platform that could be used by laboratories in Europe and in the USA for certification.
\end{abstract}

Basophil activation test: mechanisms and considerations for use in clinical trials and clinical practice

Running title: BAT in allergy research and clinical practice

Alexandra F. Santos ${ }^{1,2,3,4}$, Oral Alpan ${ }^{5}$, Hans-Jürgen Hoffmann ${ }^{6,7}$

${ }^{1}$ Department of Women and Children's Health (Pediatric Allergy), School of Life Course Sciences, Faculty of Life Sciences and Medicine, King's College London, London, United Kingdom

${ }^{2}$ Peter Gorer Department of Immunobiology, School of Immunology and Microbial Sciences, King's College London, London, United Kingdom

${ }^{3}$ Asthma UK Centre in Allergic Mechanisms of Asthma, London, United Kingdom

${ }^{4}$ Children's Allergy Service, Evelina London Children's Hospital, Guy's and St Thomas' Hospital, London, United Kingdom

${ }^{5}$ Amerimmune, Fairfax, VA, U.S.A.

${ }^{6}$ Department of Clinical Medicine, Aarhus University, Aarhus, Denmark

${ }^{7}$ Department of Respiratory Diseases and Allergy, Aarhus University Hospital, Aarhus, Denmark

Corresponding author: 
Alexandra F. Santos

Address: Department of Paediatric Allergy, $2^{\text {nd }}$ floor, South Wing, St Thomas' Hospital, SE1 7EH London, United Kingdom

Telephone number: +44(0) 2071886424

Fax number: +44 (0) 2074038640

Email address: alexandra.santos@kcl.ac.uk

Word count: 5043

Abstract: The basophil activation test (BAT) is a functional assay that measures the degree of degranulation following stimulation with allergen or controls by flow cytometry and is directly correlated with histamine release. From the bell-shaped curve resulting from BAT in allergic patients, basophil reactivity (given by \%CD63+ basophils) and basophil sensitivity (given by EC50 or similar) are the main outcomes of the test. BAT takes into account all characteristics of IgE and allergen and thus can be more specific than sensitization tests in the diagnosis of allergic disease. BAT reduces the need for in vivo procedures, such as intradermal tests and allergen challenges, which can cause allergic reactions of unpredictable severity. As it closely reflects the patients' phenotype, it can potentially be used to monitor the natural resolution of food allergies and to predict and monitor clinical response to immunomodulatory treatments, such as allergenspecific immunotherapy and biologicals. Clinical application of BAT requires analytical validation, clinical validation, standardization of procedures and quality assurance to ensure reproducibility and reliability of results. Currently, efforts are ongoing to establish a platform that could be used by laboratories in Europe and in the USA for certification.

Abstract word count: 190

Keywords: allergy, anaphylaxis, basophil activation test, CD63, diagnosis, immunotherapy

Statement of contribution by each named author: A.F.S. defined the outline of the review, wrote the first draft of the sections about allergic reactions, immune monitoring and use in clinical trials, and coordinated the editing of the subsequent versions of the manuscript. O.A. wrote the first draft of the sections about the clinical applications of the basophil activation test. H.J.H. wrote the first draft of the sections about the basic mechanisms of basophil activation. All authors contributed to all sections and approved the final version of the manuscript prior to submission.

The basophil activation test (BAT) is a flow cytometry laboratory assay which measures the expression of activation markers on the surface of blood basophils. CD63 was discovered by Edward Knol in $1991^{1}$ and, since then, BAT has progressively gained importance in the diagnosis and monitoring of allergic diseases (Figure 1). In this review, we will cover the state-of-the-art BAT technology to explore immune mechanisms and clinical assessment of patients with suspected IgE-mediated allergic disease. As a functional assay performed on live cells following stimulation with allergen, BAT can be more specific than measuring the concentration of allergen-specific IgE. Furthermore, as a laboratory test, BAT avoids exposure of patients to the allergen being investigated, thus making the diagnostic process accurate, safe and more comfortable for patients and their families.

\section{Basic principles of BAT}

BAT focuses on the basophil population at a single cell level using flow cytometry and allows the assessment of the activation state of these cells before and after stimulation with allergens or controls. Basophils have low side scatter, intermediate between lymphocytes and monocytes, and can be identified through a number of near-unique selection markers: CD193 ${ }^{+}$(also expressed on SSC ${ }^{\text {high }}$ eosinophils), CD123 $3^{+}$(also expressed on HLA-DR $^{+}$plasmacytoid dendritic cells) and CD203c and FceRI are also expressed on pluripotent progenitors of mast cells. Common methods of identifying basophils are as $\mathrm{SSC}^{\text {low }} \mathrm{CD} 193^{+} \mathrm{CD} 203 \mathrm{c}^{+}, \mathrm{CD} 123^{+} \mathrm{HLA}^{-\mathrm{DR}}{ }^{-}$, $\mathrm{CD} 123^{+}$HLADR-, CD203c ${ }^{+}$or $\mathrm{CD} 193^{+} \mathrm{CD} 123^{+2,3,4}$. FceRI and IgE, when used as selection markers in 
isolation, have the disadvantages of varying with plasma concentration of $\operatorname{IgE}$ and of inducing activation of the IgE-mediated pathway leading to degranulation. Figure 2shows examples of gating strategies used in assays used clinically and for research purposes.

Activation of basophils can be detected through upregulation of selected surface proteins; of which CD63 is the most commonly used activation marker ${ }^{1}$ and CD203c is upregulated slightly earlier ${ }^{5,6}$. CD107a and CD107b co-localise with CD63 in secretory lysozymes, whereas CD164 and CD13 co-localise with CD203c in vesicles distinct from these. Further, upregulation of CD18/CD11b ${ }^{1}$ and $C D 45$ can also be detected, but these are not nearly as dichotomous as the upregulation of CD63. The tetraspanin CD63 is located in the membrane of secretory lysosomes in basophil granulocytes ${ }^{1}$ and mast cells ${ }^{7}$. It is a 4 -transmembrane protein that may be associated with reorganisation of the cell membrane ${ }^{8}$ and with exosome formation ${ }^{9}$. Its role in these processes is not yet well understood, but it is very useful as a biomarker of basophil activation. The expression of CD63 on the surface of basophils is directly and strongly correlated with histamine released into the cell supernatant ${ }^{1,10,11}$.

\section{Basophil signalling in IgE-mediated basophil degranulation}

Crosslinking of IgE presented on FceRI, the high affinity IgE receptor on blood basophils, results in increased phosphorylation of ITAMs of the FceRI?? subunits, and of the SH2-domains of kinases Syk and Lyn ${ }^{12}$, which are under constant counter-regulation by dephosphorylation through CD $45^{13}$. Net phosphorylation of FceRI?? and Syk leads to massive amplification of the initial signal, similar to that of neuronal signalling, and regulated exocytosis of secretory lysosomes that stain with basic dyes as they contain histamine, histidine decarboxylase, heparin and proteases ${ }^{14}$. Immune-regulated exocytosis uses SNAP23 and VAMP8 whereas SNAP25 and VAMP1 and VAMP2 are used in neuronal signalling ${ }^{15}$. Degranulation has been studied mainly in murine mast cells and the RBL cell line, as these can be cultured in sufficient quantities ${ }^{16}$. IgE-mediated activation is an example of a bi- or multivalent activation mechanism through adaptive immune signalling. Use of wortmannin sensitive kinases PI3K and MAPK can confirm the IgE-mediated origin of the activating signal ${ }^{1,17}$, since wortmannin can thus inhibit the IgE pathway. The fusion of secretory lysosomes with the cell membrane in basophil and mast cells may also be activated through G-coupled protein receptors linked to receptors for univalent exogenous substances like fMLP and ligands for MRGPRX2 ${ }^{18}$, and may be modulated by receptors for endogenous univalent substances like PAF, IL8 and C5a ${ }^{14}$.

\section{The bell-shaped dose-response}

The typical BAT result in allergic patients is a bell-shaped curve for the \%CD63-positive basophils with increasing concentrations of allergen. As the antigen-specific IgE-FceRI complex is a receptor aggregation reaction that depends on the affinity of IgE for the allergen and on the valency of the allergen, a doseresponse curve is often bell-shaped. However, the complexity of antigens and the relative affinity of different epitopes on allergens for profiles of epitope-specific IgE (bound to the cell) of different patients results in dose-response curves that vary in form. As can be seen from the variability shown by the different doseresponse curves, tests with single concentrations of antigen can be misleading. There are a number of factors that can impact the dose response curves of basophil surface activation markers such as affinity of the antigen for the IgE, epitope spreading of the IgE antibody, the density of the epitope-specific IgE on the cell surface, and an intrinsic characteristic of the basophil itself. The combination of these factors determines the optimal allergen concentration for basophil activation, thus this point might vary significantly among subjects and between different allergens in the same subject. ${ }^{19,20}$. Therefore, it is preferable to include a broad range of allergen concentrations to better appreciate the effect of the allergen on basophil response.

The importance of non-IgE and IgE-mediated controls and the enigma of non-responder basophils

The most frequently used stimulants in the BAT are allergens. However, basophils of approximately $10 \%$ of the population do not respond to stimulation through FceRI even though they express normal densities of cellsurface IgE and upregulate CD63 well to a non-IgE-dependent stimulus. One cause of non-responsiveness is a low level of Syk phosphatase ${ }^{21-23}$, possibly in combination with elevated amounts of CD $45^{13}$. The 
non-responder phase is transient; a patient may revert to a responsive state within months ${ }^{24,25}$. The nonresponder state has also been reversed experimentally in vitro by culturing basophils in the presence of IL- $3^{26}$. In a large study performed in Singapore, basophil non-responsiveness was associated with lower amounts of basophil Syk, and an apparent reduction of the incidence of rhinitis; basophil non-responsiveness thus may be a final barrier of the immune system to prevent unwanted reactions against allergens ${ }^{24}$. As the amount of allergen-specific IgE increases, the amount of basophil Syk is transiently decreased by allergen exposure to limit the allergic response. It is not clear at this time, however, whether it is the clinically relevant allergen that is modulating this basophil response.

It is important to document that the blood basophils are alive and capable of mounting a response to a non-IgE stimulus to document, i.e. that the activation test is valid. The bacterial tripeptide fMLP that activates basophils through the G-protein coupled fMLP receptors to degranulate, is often used as a non-IgE mediated positive control ${ }^{1}$. Degranulation through fMLP occurs faster that the IgE-mediated response. It is insensitive to inhibitors like Staurosporine and Wortmannin, that inhibit IgE-mediated degranulation ${ }^{27}$. After confirming that blood basophils respond to fMLP, it is important to assess whether they respond to IgE-mediated controls. Blood basophils of non-responders do not get activated in response to a stimulus through IgE/FceRI, i.e. they do not upregulate CD63 or release histamine.

\section{Parameters that can influence the results of the basophil activation test}

Various factors can affect the results of the BAT, for instance: time between blood collection and the performance of BAT, medication that the patient being tested may be on, material used for basophil stimulation, antibodies used for staining of key markers and flow cytometry analyses.

Blood basophils are best used fresh, ideally on the same day or up to 24 hours of blood collection ${ }^{28}$. It is possible to obtain a positive result after two days ${ }^{28,29}$; however, that result may not be the same to that obtained with fresh blood basophils ${ }^{28}$. Individuals being tested on BAT should stop treatment with oral steroids three weeks before the test ${ }^{30}$. Antihistamines and topical treatments do not influence the result of $\mathrm{BAT}^{30}$.

Ideally, standardized extracts, recombinant or purified allergens or parenteral drug preparations should be used for the BAT, and, if necessary, the patient can bring the relevant allergen with them (Peppys principle) ${ }^{3}$. An allergen the patient brings can be solubilized according to standard methods ${ }^{3}$, and should be used at concentrations not toxic to blood. Typically, less than $1 \% \mathrm{w} / \mathrm{v}$ is a high concentration that can be tolerated, and response to more than four sequential log dilutions of allergen should be determined. Allergen extracts should be clearly defined in terms of protein and major allergen concentration. Molecular allergens should be defined in mole of allergen. Basophil testing is surprisingly resilient to selection of fluorochrome-conjugated antibodies used, and the method of warming up the cells to respond ${ }^{31}$.

Activated basophils are identified by measuring the percentage of CD63 positive cells and the fold change in CD203c MFI compared to negative control. During the gating analysis, it is important to have the same threshold set on a negative control at the same level of reactivity. When diagnosing drug allergy, a threshold of $2.5 \% \mathrm{CD} 63+$ basophils in the unstimulated condition gives the best results ${ }^{31}$. Methods to use automated data analyses have been developed and have the advantage of being more standardised and objective compared to manual gating, which is still considered the gold-standard ${ }^{32}$.

\section{Reactivity and sensitivity are distinct measures of basophil response}

Basophil reactivity refers to the proportion of basophils that express CD63 compared to the negative control and can be expressed as $\% \mathrm{CD} 3^{+}$basophils at a given allergen concentration or as the ratio of $\% \mathrm{CD} 63^{+}$to allergen and the $\operatorname{IgE}$-mediated positive control (anti-IgE or anti-FceRI). It serves to document the presence of biologically relevant sensitisation to allergen through IgE. Basophil reactivity needs to be measured before sensitivity can be assessed and should hence be reported first. Two recent studies of peanut allergy found a relationship of reactivity and symptom severity ${ }^{25,33}$; however, in a study of wasp venom allergy, basophil reactivity to wasp allergen extract could not predict patients symptom severity ${ }^{34}$. The latter study set the 
scene for developing methods to assess basophil sensitivity ${ }^{35}$, that has been shown to be useful in the diagnosis of allergic asthma ${ }^{36}$, rhinitis ${ }^{37}$, food allergy ${ }^{33,38-40}$, allergen immunotherapy ${ }^{41-45}$ and anti-IgE therapy ${ }^{46-48}$.

Basophil sensitivity refers to the allergen concentration eliciting half-maximal basophil activation and can be expressed as $\mathrm{EC}_{50}$ that decreases with increasing severity ${ }^{42,45}$, or CD-sens which is the inverse of $\mathrm{EC}_{50}$ multiplied by 100 and can be calculated based on the slope of the dose-response curve ${ }^{25,35}$. CD-sens increases with the severity of allergic reactions ${ }^{35}$. Determination of sensitivity of basophils to allergen by flow cytometry was preceded by studies determining basophil sensitivity to allergen by measuring the release of histamine, $\mathrm{PGD}_{2}$ or Cys-Leukotrienes ${ }^{3}$. Activation of blood basophils should be assessed at each of 5-12 log dilutions of allergen. The degree of reactivity at each allergen concentration is plotted against allergen concentration, and both maximal reactivity and half-maximal reactivity are determined by fitting a non-linear curve to the dose-response. Basophil sensitivity correlates with the patient's sensitivity to allergen at the clinical level, both in respiratory ${ }^{36,49}$ and in food allergies ${ }^{25,38-40,50}$ and changes in sensitivity reflect the clinical improvement in allergic rhinitis ${ }^{41,42,44,45,51,52}$. Basophil reactivity and basophil sensitivity appeared to be distinct parameters of activation ${ }^{53,54}$; however, systematic analyses of signalling molecules in the pathway leading from IgE crosslinking to degranulation show that are interdependent and regulated by $\mathrm{syk}^{55,56}$.

\section{What can BAT tell us about allergic reactions?}

Acute immediate allergic reactions and anaphylaxis result from the effect of mediators released by basophils and mast cells following exposure to the allergen. Blood basophils are more readily available in peripheral blood than tissue mast cells are and thus constitute an accessible relevant sample to study immediate allergic reactions and anaphylaxis. The BAT has shown to reflect the allergic status of patients sensitized to food, inhalant and insect venom allergens in different studies, with the basophils of allergic subjects typically showing a dose-dependent increase in the \%CD63+ basophils or in the mean fluorescence intensity of CD203c 57,58 . Such studies have led to a growing force into applying BAT to the diagnosis of IgE-mediated allergic disease, given its very high specificity with retained high sensitivity compared to IgE sensitization tests. In a peanut allergy study ${ }^{40}$, which was recently validated further ${ }^{59}$, the specificity of BAT to peanut ranged between 96 and $100 \%$. Such high specificity strongly supports its use to confirm the diagnosis of food allergy and dispense patients from risky and stressful exposure to the allergen during challenges ${ }^{60}$. In patients with allergic asthma, CD-sens was correlated with allergen dose used in bronchial challenge causing a $20 \%$ drop in forced expiratory volume in $1 \mathrm{~s}\left(\mathrm{PD}_{20}\right)$. This correlation was mostly due to patients with low $\mathrm{AHR}$ and was not seen in patients reacting with high AHR, which further suggests that this correlation is allergen-specific and that BAT reflects the allergic component in the bronchial responsiveness ${ }^{36}$. In venom allergy, BAT can add clinical value to IgE testing and can be particularly useful in cases of undetectable IgE sensitization or double sensitization to both wasp and bee venom ${ }^{61}$. BAT may also be valuable in replacing sting challenges to guide when to stop immunotherapy ${ }^{62}$.

BAT can also be useful to recognise more detailed aspects of allergic patients' phenotype. For instance, patients with different phenotypes of milk and egg allergy have shown different profiles of CD63 upregulation following allergen stimulation with children tolerating baked milk/egg while reacting to fresh milk/whole egg showing an intermediate degree of basophil activation between children who were allergic to all forms of milk and children who had outgrown their milk/egg allergy ${ }^{63,64}$. A greater proportion of activated basophils has been associated with increasing severity of allergic reactions and basophil sensitivity with the threshold dose at which patients reacted during challenges to peanut ${ }^{33,59,65-68}$. This is another example of how BAT can be used to define more subtle characteristics of the allergic response beyond the dichotomic classification of allergic versus non-allergic.

Apart from identifying patients' allergic status at a given time-point, BAT may be a useful tool to monitor natural changes in allergic status over time or with immunomodulatory treatments. Various studies have documented a decrease in basophil reactivity and sensitivity following allergen specific immunotherapy to food, respiratory and insect venom allergens ${ }^{42,45,69-71}$. In food allergy, a decrease in basophil reactivity during treatment has been observed to the culprit allergen and a bystander allergen as well as IgE-mediated (but not non-IgE-mediated) positive controls suggesting changes intrinsic to the basophil. These changes, which 
are typical of basophil anergy, accompany clinical desensitization to the allergen, as measured by the increase in threshold of reactivity while on treatment ${ }^{72}$. The decrease in basophil reactivity can be more notorious in oral compared to sublingual immunotherapy to foods, mirroring the difference in efficacy of OIT compared with SLIT in terms of the dose of allergen tolerated during treatment ${ }^{73}$. The reduction in basophil reactivity can be transient, which is similar to the clinical effect of oral immunotherapy in some patients following discontinuation of treatment ${ }^{73}$, hence a good test to monitor relapse of the allergy.

\section{Changes in BAT with immunomodulatory treatments}

As basophils express FceRI and bear IgE, they are an effector cell of interest to explore the long-term effects of immunotherapy ${ }^{74}$; the suppressive effects of blocking antibodies induced during treatment. A change in basophil sensitivity during the first three weeks of allergen immunotherapy correlated strongly with the clinical effect of treatment during the first year ${ }^{42}$ as well as three years of treatment ${ }^{45}$ and could be developed into a diagnostic biomarker for allergen immunotherapy. Passive sensitization approaches in which pre and post-treatment plasma are used to sensitize primary basophils or to pre-incubate with allergen prior to adding sensitized cells are ways to assess the function and suppressive effects of post-treatment plasma containing blocking antibodies ${ }^{62,75,76}$. Another experimental setup that can be used to explore the effects of blocking antibodies is the washed BAT, in which plasma surrounding basophils is removed, and its comparison with whole blood $\mathrm{BAT}^{42}$. Typically, post-treatment plasma contain allergen-specific antibodies of different isotypes to IgE, namely IgG and IgA, that compete with $\operatorname{IgE}$ for allergen binding reducing the amount of allergen that is able to cross-link IgE antibodies on the surface of mast cells and basophils and therefore reducing the chance of inducing an allergic reaction or its severity ${ }^{77}$. Evidence that blocking antibodies can induce inhibitory cell signalling through ITIM-coupled receptors is lacking in natural tolerance or desensitization through IT ${ }^{78}$. The use of specific inhibitors of signalling molecules downstream the high-affinity IgE receptor can help to confirm whether observed effects of treatment are IgE-mediated.

BAT has also shown to be useful in monitoring the response to treatment with omalizumab ${ }^{47,79-81}$. In a peanut study, the BAT was used to make decisions about the need to adjust the dose of omalizumab ${ }^{82}$. Given that the anti-IgE antibody captures IgE in circulation and reduces the $\operatorname{IgE}$ that is bound to receptors on the surface of circulating basophils and tissue mast cells, it leads to a progressive reduction in surface expression of FceRI on effector cells, and in response to the allergen in vitro in the BAT ${ }^{47,48,83}$. However, because the reduction in receptor density on the surface of these effector cells enhances their intrinsic sensitivity ${ }^{84}$, omalizumab can paradoxically increase basophil reactivity to the allergen. As a result, the patients that are most likely to better respond to omalizumab are the one with higher allergen specific activity, i.e. the ones whose proportion of $\mathrm{IgE}$ that is allergen-specific is higher ${ }^{85,86}$. BAT can potentially be useful in monitoring the clinical response to other biologicals in terms of their effect on the risk of acute reactions to a given allergen.

\section{The use of the basophil activation test in clinical trials}

BAT has a huge potential in clinical trials, both as a biomarker of clinical response to treatment and in the exploration of possible underlying mechanisms at the effector cell level. However, there are practical aspects that need to be considered in order for the results to be informative, reproducible and comparable between sites. Table 1 presents some of the practical issues and recommendations to circumvent them and reach an optimal use of BAT in the context of clinical trials.

In addition to being a surrogate of clinical outcomes of therapies, a key application of BAT in future clinical trials is to confirm eligibility of patients for allergy treatment. This is particularly important in the context of food allergy, for which, at the moment eligibility for food IT requires the performance of allergen challenge in patients that have been previously diagnosed with food allergy. Having to undergo an oral food challenge for a patient known to be allergic can be quite stressful and additional challenges are often required in study protocols to assess clinical response to IT. This approach is unlikely to be well accepted by patients and families in clinical practice, as patients being considered for treatment have already been diagnosed with food allergy and may be fearful of exposure to the allergen, even in the context of an oral food challenge. Depending 
on the threshold of reactivity required, challenges done as part of study protocols can exclude allergic patients with high threshold of reactivity that would otherwise benefit from such treatment. Similar considerations can be made for biologicals, which are often reserved for patients with severe allergic conditions, that may be at additional risk of undesirable outcomes during allergen challenges.

\section{The use of basophil activation test in clinical practice}

The BAT can have different applications in the day-to-day clinical setting - Table 2 summarises some of the possible indications of BAT, which can be categorized into three main groups: 1) confirmation of an allergy, 2) eligibility for a specific therapy and 3) monitoring of the natural resolution of an allergy or response to therapy. The confirmation of allergy is important for several reasons. Firstly, it improves the safety profile of diagnostic work-up, as it may defer the need for an oral food challenge, preventing potential anaphylactic reactions. Secondly, it allows confirming the indication for immune modifying therapies that may require prolonged exposure to medications before a clinical response is seen. Examples for this is the use of omalizumab in allergic asthma and initiation of oral food immunotherapy, both of which require many months on therapy to assess response. Thirdly, BAT may be useful to measure the response to treatment and act as a surrogate of in vivo allergen exposure, like in a food challenge. Even in cases where basophils show no response to allergen and the positive control, ? $\operatorname{IgE}$ (known as non-releaser or anergic basophils), data is emerging that is suggestive of this finding is more likely to indicate low clinical reactivity to allergen (24). Furthermore, BAT also has value in rare allergic disorders, such as allergic bronchopulmonary aspergillosis, as an additional criterion for diagnosis, particularly in patients who do not fulfill the minimal diagnostic criteria.

The use of the BAT to clinical practice requires analytical validation of the methodology, clinical validation of the test against patients' phenotype and continued quality assurance ${ }^{57,87-89}$.

Analytical validation of the basophil activation test

Analytical validation determines the accuracy of the testing procedure from the draw of the blood sample to the reporting of the results. There are several important components of the analytical validation of a basophil activation test ${ }^{90}$ :

- Inter and intra-run precision: Inter-run precision analyses samples at different time points, whereas intra-run precision assays for repeats of samples at the same time point on the same day. The precision analysis for the BAT shows good correlation ${ }^{88}$.

- Analytical interferences : A given allergen does not stimulate/induce basophils of non-allergic patients and basophil activation in a given patient are specific to the allergen being tested and the concentration of the allergen. A given concentration of allergen does not induce the same basophil response in all patients, hence the importance of clinical correlations for each allergen at a number of concentrations.

- Stability of samples : The question of stability of the samples before reaching the laboratory has mostly been resolved ${ }^{91}$. When transported in heparin tubes, samples can stay stable up to 24 hours even when shipped in ambient conditions. EDTA is an alternative calcium chelating anticoagulant that stabilises basophils before testing. Allergens should be prepared freshly, even if previously stored frozen or lyophylised.

- Proficiency Testing: For a sustained high quality use of BAT in the clinical setting, constant quality control is necessary. In 2017 the EU approved the in vitro diagnostic medical devices regulation (IVDR), that has to be implemented by $2024^{92}$. Since BAT is not a widely available assay and regulatory bodies have not yet established proficiency testing, laboratories have created individualized quality control measures to assure that the validated assays continue to perform accurately. RfB (www.rfb.bio) and INSTAND (www.instand-ev.de) are planning to offer external quality assurance systems. Standardization of BAT procedures, allergen preparations and sharing databases in which annotated raw data can be deposited are important as it allows comparison of results in different centers and would ensure consistency.

It is important to note that regulations and reimbursement/coverage by healthcare systems vary for flow 
cytometry based assays in different parts of the world. In the United States, BAT is used as a diagnostic test as a part of clinical decision making in allergy practices that has the capabilities of a high-complexity flow cytometry laboratory ${ }^{93-95}$. At the time of this review there are such set-ups in private clinical practice as well as academic institutions. In Europe, the BAT is mostly used in research and has been adopted as a clinical test in some countries, such as Sweden, Spain, Germany and Italy. Basophil testing has gained acceptance throughout the world, including South Africa, Eastern Europe and South America. Many allergy clinics use in house procedures (also referred to as "Laboratory Developed Tests") detecting CD63, others use kits that are commercially available.

Clinical validation of the basophil activation test

An essential aspect of clinical validation of BAT is to determine its sensitivity and specificity for clinical correlates of interest. The sensitivity and specificity of BAT for food allergies are high, despite showing significant differences between foods. The sensitivity of BAT for drug allergies are lower, but still BAT can be extremely useful in the case of life-threatening drug allergies in which patients cannot be re-challenged or in the case of drugs for which no other tests are available. A summary of the specificity and sensitivity can be seen onTable 3 and has been previously reviewed ${ }^{3,58}$.

Food allergy is the area of Allergology in which there is the largest evidence about the diagnostic performance and cut-offs for tests, such as specific IgE and skin prick testing, and in which some of the largest studies on the clinical utility of the BAT were done. Although the SPT and specific IgE are very sensitive and positive cut-offs have been determined to improve their specificity, the majority of food sensitized patients fall into an immunologically grey area, i.e. have results for SPT and specific IgE that are detectable but below the $95 \%$ PPV cut-off. For most foods, this immunologically grey zone is wide and in such cases, BAT provides significant value in differentiating those with true allergy from sensitization. Even for foods for which there are informative allergen components, for instance Ara h 2 in the case of peanut, BAT can clarify equivocal cases and reduce the number of patients requiring OFC. The gold-standard for the diagnosis of food allergy is OFC. It can lead to severe acute allergic reactions, needs to be performed in a supervised environment with the facilities and expertise to treat allergic reactions and anaphylaxis, should they occur and cause significant anxiety in patients, parents and even clinical staff. Given its strong correlation with clinical reactions, BAT offers an important safe intermediate test before a food challenge is considered.

OFC is often also required to confirm eligibility for treatments for food allergy, such as OIT. For clinics that do not routinely perform OFC before starting OIT, BAT can be used as an alternative to identify allergic patients. BAT may also provide prognostic information about which patients would benefit the most from this treatment ${ }^{76}$. In a peanut OIT study, participants entering the study with low basophil responsiveness were more likely to achieve treatment success ${ }^{96}$. In another study, using grass pollen SCIT, basophil sensitivity improved within three weeks of the start of the allergen immunotherapy (AIT) and correlated with clinical outcomes after three and four years based on in vivo allergen challenge ${ }^{45}$.

The success of the BAT is influenced by patient selection, allergens used and criteria for cut-off values ${ }^{60}$. There are also practical issues to consider when incorporating BAT as part of routine diagnostic work up. For instance, although BAT to peanut showed overall best diagnostic accuracy compared to all other tests available $^{40}$, it is easier to perform skin prick test or specific $\operatorname{IgE}$ and therefore these tests can be used as first line. BAT should be performed as a second-line test in patients with equivocal outcome following clinical history and IgE sensitization tests ${ }^{57}$, before referring patients for OFC. This proposed approach reduced the number of OFC by $67 \%$ in a previous study of peanut allergy ${ }^{40}$. To circumvent the major limitations of BAT, which are the need for fresh blood and the 10-15\% non-responders, the mast cell activation test (MAT) may be used to complement the $\mathrm{BAT}^{97}$.

Quality assurance of the basophil activation test

For a sustained high-quality use of BAT in the clinical setting, constant quality control, as laid out in ISO 15189:2012, ISO15189:2013 and ISO 9001:2016, is necessary and increasingly required by national legislation. For the test to be reimbursed by health care systems and insurance companies, rigorous quality assurance 
process needs to be in place in certified laboratories.

Representatives of European laboratories developing basophil testing have discussed opportunities of basophil testing since $2006^{98,99}$, and have met regularly in the EUROBAT meeting series to strengthen the development of basophil tests. These meetings continue every second year under the auspices of the Interest Group Allergy Diagnosis and Systems Medicine within EAACI. To meet the increasing demand for certification described in ISO 9001/15189 for biomedical laboratories, the European Academy of Allergy and Clinical Immunology launched a task force with the aim of standardizing basophil testing and establishing external quality assurance under the control of EAACI. Engaging EAACI as the European organisation representing professionals working with allergy in quality assurance of a cutting-edge diagnostic test would uniquely enhance the quality of the test. To our surprise, standardizing the method of analysis dramatically improved coherence of the results (CV $<10 \%$ for detection of $\mathrm{CD} 63^{+}$basophils) in ten European laboratories ${ }^{31}$, suggesting that the standardization of reagents used may be of minor importance. As this is in stark contrast to the heterogeneity of results obtained in external quality assurance of IgE testing ${ }^{100}$, it is important to maintain the momentum of this process and bring it to IgE testing as well.

At the present time, in the United States, there are 9 laboratories in 6 states, that provide BAT for the common food allergens with an inter-laboratory quality assurance system in place and harmonized protocols. Similar to its European counterpart, AmeriBAT was created between these laboratories that offer clinical grade BAT to establish a network of quality assurance and control (QA/QC). In this quarterly process, a blood sample from Donor A is processed the day it is collected (Day 0) in Lab 1 and then mailed to lab 2 where it is processed the following day (Day 1) and a blood sample from Donor B is processed in lab 2 on Day 0 and mailed to Lab 1 for processing on Day 1. The temperature during shipping is measured with a temperature strip to ensure that the sample is within $2-37 \mathrm{C}$ range. The $\% \mathrm{CV}$ between the results for the two locations should be below $25 \%$ but results as high as $35 \%$ can be accepted as basophils can be considered rare events in whole blood.

\section{Conclusion}

The BAT can be seen as a surrogate of immediate allergic reactions in vitro and thus support the diagnosis of allergic diseases and its monitoring during immunomodulatory treatments (Table 4). A robust laboratory method which can provide consistent and reliable results that have been clinically validated can be extremely valuable both for clinical practice and for clinical trials into existing and novel treatments for allergic disease. Standardisation and continuous quality assurance as well as training of health care professionals on the interpretation of BAT results are important for further implementation of BAT in clinical practice and allergy research.

Tables:

Table 1. Practical issues and considerations for optimal use of BAT in clinical trials.

\begin{tabular}{lll}
\hline Practical issues & Recommendations & $\begin{array}{l}\text { Implications for clinical } \\
\text { trials }\end{array}$ \\
\hline $\begin{array}{l}\text { Basophil reactivity is reduced } \\
\text { over time }\end{array}$ & $\begin{array}{l}\text { Perform BAT within a few hours } \\
\text { (up to 24h) of blood collection }\end{array}$ & $\begin{array}{l}\text { Good transportation system } \\
\text { between sites to ensure timely } \\
\text { delivery of samples. Test samples } \\
\text { of all site within the same time } \\
\text { frame. }\end{array}$ \\
$\begin{array}{l}\text { Basophil reactivity can be } \\
\text { affected by vibration and changes } \\
\text { in temperature } 29\end{array}$ & $\begin{array}{l}\text { Ensure method of transportation } \\
\text { that ensure stability of } \\
\text { temperature transfer of samples. }\end{array}$ & $\begin{array}{l}\text { Prefer transport system with } \\
\text { temperature control for samples. }\end{array}$
\end{tabular}

in temperature ${ }^{29}$.

temperature transfer of samples. 


\begin{tabular}{|c|c|c|}
\hline Practical issues & Recommendations & $\begin{array}{l}\text { Implications for clinical } \\
\text { trials }\end{array}$ \\
\hline $\begin{array}{l}\text { Immunosupressors, including oral } \\
\text { corticosteroids, can reduce } \\
\text { basophil response }{ }^{30} \text {. }\end{array}$ & $\begin{array}{l}\text { Avoid immunosupressors before } \\
\text { blood collection for BAT. }\end{array}$ & $\begin{array}{l}\text { Need to continue treatment with } \\
\text { immunosupressors should be an } \\
\text { exclusion criteria of studies using } \\
\text { BAT. }\end{array}$ \\
\hline $\begin{array}{l}\text { Exposure to allergen, chronic } \\
\text { inflammation and infection can } \\
\text { induce basophil degranulation and } \\
\text { homing to the tissues }^{101} \text {. }\end{array}$ & $\begin{array}{l}\text { Avoid performing BAT after } \\
\text { allergen exposure or during } \\
\text { infection or chronic inflammatory } \\
\text { condition. }\end{array}$ & $\begin{array}{l}\text { Blood for BAT needs to be } \\
\text { collected prior to allergen } \\
\text { exposure (namely challenge but } \\
\text { not SPT). Active infections } \\
\text { inflammatory conditions should } \\
\text { be an exclusion criteria of studies } \\
\text { using BAT. }\end{array}$ \\
\hline $\begin{array}{l}\text { Basophil activation can vary } \\
\text { with the anticoagulant used }{ }^{29} \text {. }\end{array}$ & $\begin{array}{l}\text { BAT can be performed in blood } \\
\text { collected into heparin or EDTA. }\end{array}$ & $\begin{array}{l}\text { Blood for BAT should be } \\
\text { collected using the same } \\
\text { material and methodology } \\
\text { during studies and between } \\
\text { sites. }\end{array}$ \\
\hline $\begin{array}{l}\text { Measurement of basophil } \\
\text { activation can be influenced by } \\
\text { the markers used to identify the } \\
\text { basophils, by the BAT protocol } \\
\text { and by flow cytometry }{ }^{4} \text {. }\end{array}$ & $\begin{array}{l}\text { BAT should be performed with } \\
\text { a validated method and } \\
\text { optimised conditions. }\end{array}$ & $\begin{array}{l}\text { The same reagents and protocol } \\
\text { should be used throughout a } \\
\text { clinical trial and flow } \\
\text { cytometers should be } \\
\text { standardized. }\end{array}$ \\
\hline $\begin{array}{l}\text { Quantification of basophil } \\
\text { activation can vary with the } \\
\text { method adopted for data } \\
\text { analyses }{ }^{4,32} \text {. }\end{array}$ & $\begin{array}{l}\text { Criteria should be defined for } \\
\text { each step of data analyses. } \\
\text { Automated data analyses can } \\
\text { be considered. }\end{array}$ & $\begin{array}{l}\text { The exact same methodology } \\
\text { needs to be used between } \\
\text { centers and throughout the } \\
\text { clinical trial. }\end{array}$ \\
\hline
\end{tabular}

Table 2. Indications for the basophil activation test in the clinical setting.

Table 3. Sensitivity and specificity of the basophil activation test to diagnose different allergic conditions.

\begin{tabular}{|c|c|c|c|c|c|}
\hline $\begin{array}{l}\text { Allergic } \\
\text { disease }\end{array}$ & Examples & $\begin{array}{l}\text { Allergen } \\
\text { stimulation }\end{array}$ & $\begin{array}{l}\text { Optimal } \\
\text { cut-off }\end{array}$ & Sensitivity & Specificity \\
\hline \multirow[t]{2}{*}{ Food allergy } & Peanut allergy ${ }^{40}$ & $\begin{array}{l}\text { Peanut extract } \\
10 \mathrm{ng} / \mathrm{mL}\end{array}$ & $\begin{array}{l}8.11 \% \text { CD } 63+ \\
\text { basophils }\end{array}$ & $98 \%$ & $96 \%$ \\
\hline & Egg allergy ${ }^{102}$ & $\begin{array}{l}\text { Ovalbumin } \\
10 \mathrm{ug} / \mathrm{mL}\end{array}$ & $\begin{array}{l}5 \% \text { CD63+ } \\
\text { basophils }\end{array}$ & $77 \%$ & $100 \%$ \\
\hline \multirow[t]{2}{*}{ Drug allergy } & $\begin{array}{l}\text { Beta- } \\
\text { lactams }{ }^{103}\end{array}$ & Various & $\begin{array}{l}5 \% \text { CD } 63+ \\
\text { basophils }\end{array}$ & $55 \%$ & $80 \%$ \\
\hline & $\begin{array}{l}\text { Neuro- } \\
\text { muscular } \\
\text { blocking } \\
\text { agents }^{104}\end{array}$ & Rocuronium & $\begin{array}{l}4 \% \text { CD } 63+ \\
\text { basophils }\end{array}$ & $80 \%$ & $96 \%$ \\
\hline \multirow[t]{2}{*}{$\begin{array}{l}\text { Insect } \\
\text { venom } \\
\text { allergy }\end{array}$} & $\begin{array}{l}\text { Wasp } \\
\text { venom }^{105}\end{array}$ & $\begin{array}{l}\text { Wasp venom, } \\
0.0001-1 \\
\mathrm{ug} / \mathrm{ml}\end{array}$ & $\begin{array}{l}10 \% \text { CD } 63+ \\
\text { basophils }\end{array}$ & $85 \%$ & $83 \%$ \\
\hline & Bee venom ${ }^{105}$ & $\begin{array}{l}\text { Bee venom, } \\
0.0001-1 \\
\mathrm{ug} / \mathrm{ml}\end{array}$ & $\begin{array}{l}\text { 10\% CD } 63+ \\
\text { basophils }\end{array}$ & $91 \%$ & $93 \%$ \\
\hline
\end{tabular}




\begin{tabular}{llllll}
\hline $\begin{array}{l}\text { Allergic } \\
\text { disease }\end{array}$ & Examples & $\begin{array}{l}\text { Allergen } \\
\text { stimulation }\end{array}$ & $\begin{array}{l}\text { Optimal } \\
\text { cut-off }\end{array}$ & Sensitivity & Specificity \\
\hline $\begin{array}{l}\text { Respiratory } \\
\text { allergy }\end{array}$ & Grass pollen $^{36}$ & $\begin{array}{l}\text { Grass pollen } \\
\text { extract, 100 - }\end{array}$ & $\begin{array}{l}2.5 \% \text { CD63+ } \\
\text { basophils }\end{array}$ & ND & ND \\
& & $\begin{array}{l}0.0001 \\
\text { SQU/ml } \\
\text { A fumigatus } \\
\text { extract (10 ul) } \\
\text { or rAsp f 1 }\end{array}$ & ND & ND & ND \\
& Aspergillus $^{106}$ & & \\
\hline
\end{tabular}

Table 4. Clinical applications of the basophil activation test.

Key clinical messages

A basophil activation test above the positive cut-off confirms the diagnosis of IgE-mediated allergy. Basophil reactivity and

Figures and figure legends:

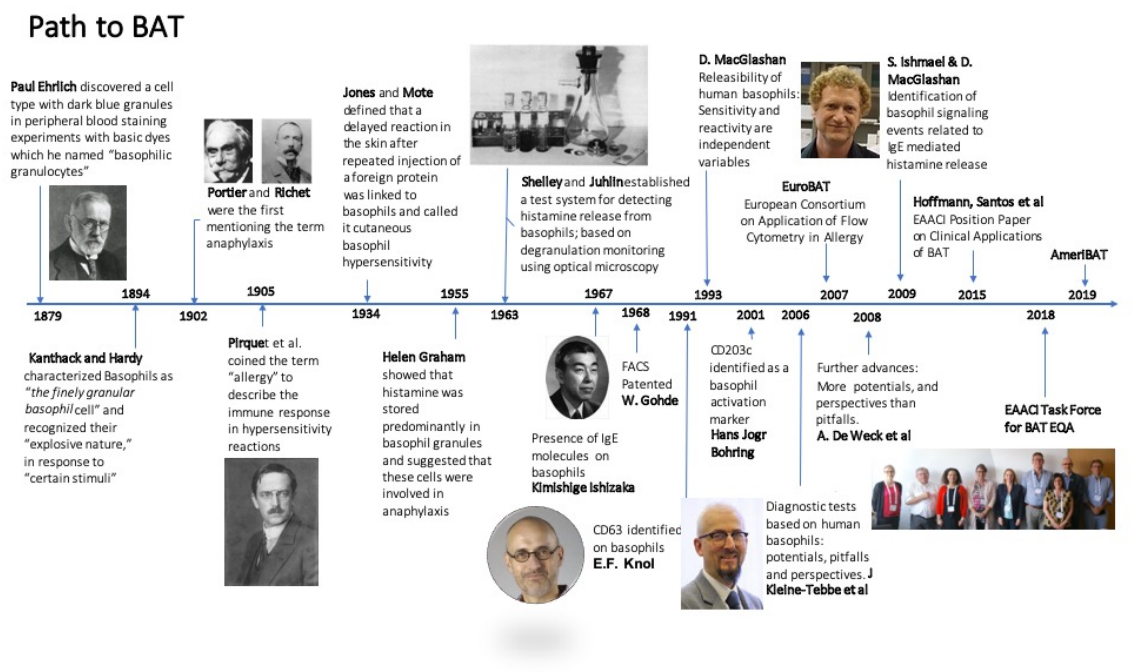

Figure 1. Historical time-line of the basophil activation test (BAT). EQA, quality assurance.

Figure 2: Examples of gating strategies for basophils:

1. Basophils were identified as SSClow CD123c+ CD193+ cells: 1. Lymphocyte - monocyte gate on a FSC/SSC plot, 2. Doublet exclusion FSC-H vs FSC-A, then SSC-H vs SSC-H, 3. Gate on both markers simultaneously CD203c x CD193, 4. Set CD63 negative threshold to $2.5 \%$ (was 5\%, but is more universal at $2.5 \%), 5$. Assess the positive population.

2. Basophils were identified as SSClow CD203c+ CD123+ HLA-DR- ${ }^{4}$. The CD63 gate is set on the negative control and basophil activation is measured above the gate for the other stimulation conditions, either with allergen or positive controls.

A. 

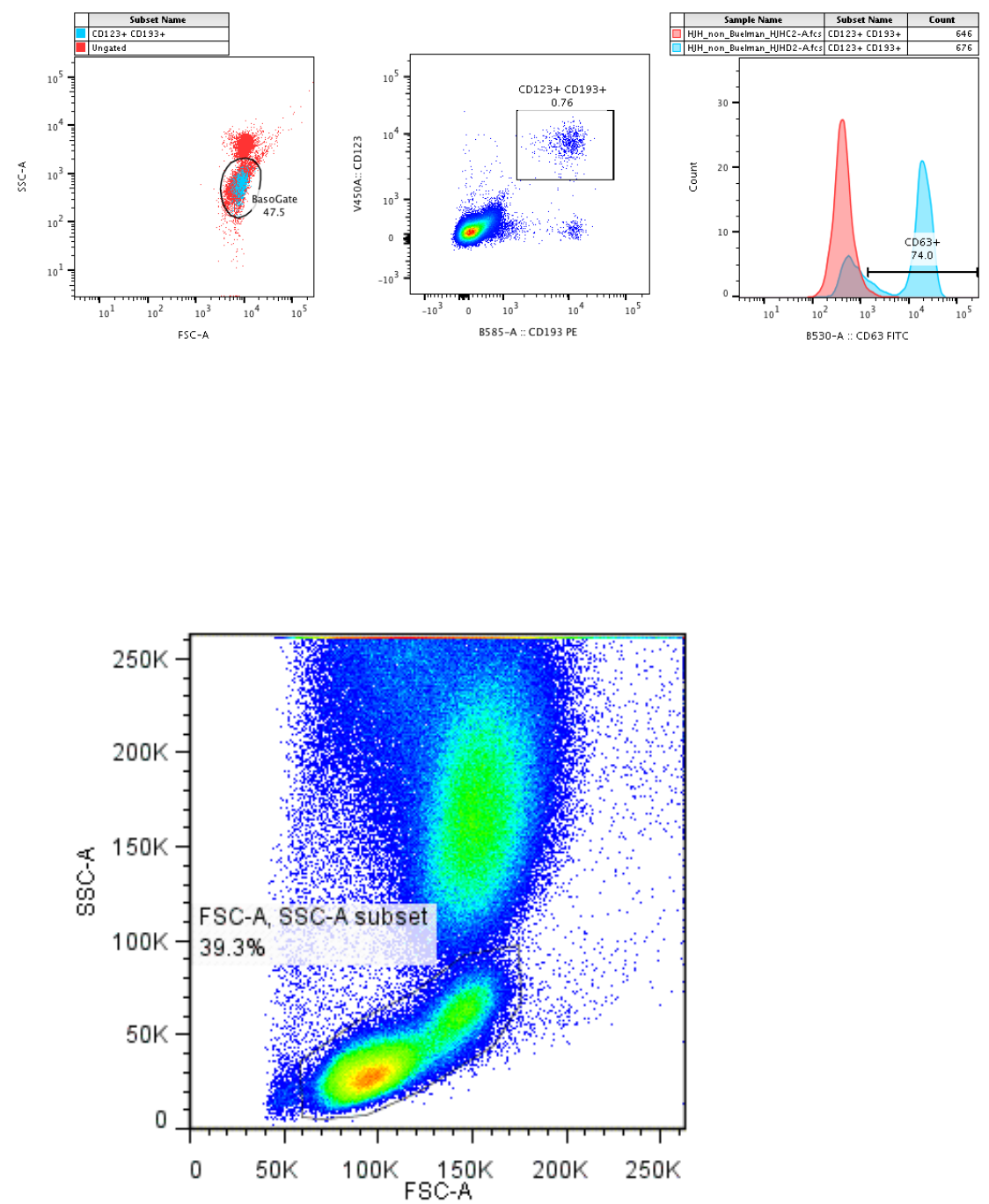

PAS 8157_Tube_001.fCS Ungated 344692 
B.

\section{References:}

1. Knol EF, Mul FP, Jansen H, Calafat J, Roos D. Monitoring human basophil activation via CD63 monoclonal antibody 435. J Allergy Clin Immunol. 1991;88(3 Pt 1):328-338.

2. Hausmann OV, Gentinetta T, Fux M, Ducrest S, Pichler WJ, Dahinden CA. Robust expression of CCR3 as a single basophil selection marker in flow cytometry. Allergy. 2011;66(1):85-91.

3. Hoffmann HJ, Santos AF, Mayorga C, et al. The clinical utility of basophil activation testing in diagnosis and monitoring of allergic disease. Allergy. 2015;70(11):1393-1405.

4. Santos AF, Becares N, Stephens A, Turcanu V, Lack G. The expression of CD123 can decrease with basophil activation: implications for the gating strategy of the basophil activation test. Clin Transl Allergy. 2016;6:11.

5. Hennersdorf F, Florian S, Jakob A, et al. Identification of CD13, CD107a, and CD164 as novel basophilactivation markers and dissection of two response patterns in time kinetics of IgE-dependent upregulation. Cell Res. 2005;15(5):325-335.

6. Smiljkovic M, Stanisavljevic D, Stojkovic D, et al. Apigenin-7-O-glucoside versus apigenin: Insight into the modes of anticandidal and cytotoxic actions. EXCLI J. 2017;16:795-807.

7. Hoffmann HJ, Frandsen PM, Christensen LH, Schiotz PO, Dahl R. Cultured human mast cells are heterogeneous for expression of the high-affinity IgE receptor FcepsilonRI. Int Arch Allergy Immunol.2012;157(3):246-250.

8. Yeung L, Hickey MJ, Wright MD. The Many and Varied Roles of Tetraspanins in Immune Cell Recruitment and Migration. Front Immunol. 2018;9:1644.

9. Shelke GV, Yin Y, Jang SC, et al. Endosomal signalling via exosome surface TGFbeta-1. J Extracell Vesicles. 2019;8(1):1650458.

10. Ebo DG, Bridts CH, Mertens CH, Hagendorens MM, Stevens WJ, De Clerck LS. Analyzing histamine release by flow cytometry (HistaFlow): a novel instrument to study the degranulation patterns of basophils. J Immunol Methods. 2012;375(1-2):30-38.

11. MacGlashan D, Jr. Expression of CD203c and CD63 in human basophils: relationship to differential regulation of piecemeal and anaphylactic degranulation processes. Clin Exp Allergy. 2010;40(9):1365-1377.

12. Hoffmann HJ, Knol EF, Ferrer M, et al. Pros and Cons of Clinical Basophil Testing (BAT). Curr Allergy Asthma Rep. 2016;16(8):56.

13. Grochowy G, Hermiston ML, Kuhny M, Weiss A, Huber M. Requirement for CD45 in fine-tuning mast cell responses mediated by different ligand-receptor systems. Cell Signal. 2009;21(8):1277-1286.

14. Xu H, Bin NR, Sugita S. Diverse exocytic pathways for mast cell mediators. Biochem Soc Trans. 2018;46(2):235-247.

15. Sander LE, Frank SP, Bolat S, et al. Vesicle associated membrane protein (VAMP)-7 and VAMP-8, but not VAMP-2 or VAMP-3, are required for activation-induced degranulation of mature human mast cells. Eur J Immunol. 2008;38(3):855-863.

16. Klein O, Sagi-Eisenberg R. Anaphylactic Degranulation of Mast Cells: Focus on Compound Exocytosis. J Immunol Res. 2019;2019:9542656.

17. Aranda A, Mayorga C, Ariza A, et al. In vitro evaluation of IgE-mediated hypersensitivity reactions to quinolones. Allergy.2011;66(2):247-254. 
18. Van Gasse AL, Elst J, Bridts CH, et al. Rocuronium Hypersensitivity: Does Off-Target Occupation of the MRGPRX2 Receptor Play a Role? J Allergy Clin Immunol Pract. 2019;7(3):998-1003.

19. Chirumbolo S, Vella A, Ortolani R, et al. Differential response of human basophil activation markers: a multi-parameter flow cytometry approach. Clin Mol Allergy. 2008;6:12.

20. Prussin C, Metcalfe DD. 5. IgE, mast cells, basophils, and eosinophils. J Allergy Clin Immunol. 2006;117(2 Suppl Mini-Primer):S450-456.

21. MacGlashan DW, Jr. Basophil activation testing. J Allergy Clin Immunol. 2013;132(4):777-787.

22. Macglashan D, Jr., Moore G, Muchhal U. Regulation of IgE-mediated signalling in human basophils by CD32b and its role in Syk down-regulation: basic mechanisms in allergic disease. Clin Exp Allergy. 2014;44(5):713-723.

23. MacGlashan D, Jr. Subthreshold desensitization of human basophils re-capitulates the loss of Syk and FcepsilonRI expression characterized by other methods of desensitization. Clin Exp Allergy.2012;42(7):10601070.

24. Puan KJ, Andiappan AK, Lee B, et al. Systematic characterization of basophil anergy. Allergy. 2017;72(3):373-384.

25. Santos AF, Du Toit G, O'Rourke C, et al. Biomarkers of severity and threshold of allergic reactions during oral peanut challenges. J Allergy Clin Immunol. 2020.

26. Schroeder JT, Chichester KL, Bieneman AP. Human basophils secrete IL-3: evidence of autocrine priming for phenotypic and functional responses in allergic disease. J Immunol. 2009;182(4):2432-2438.

27. Knol EF, Mul FP, Kuijpers TW, Verhoeven AJ, Roos D. Intracellular events in anti-IgE nonreleasing human basophils. J Allergy Clin Immunol. 1992;90(1):92-103.

28. Kwok M, Lack G, Santos AF. Improved standardisation of the whole blood basophil activation test to peanut. Clin Transl Allergy. 2017;8 (Suppl 2)(26):15-16.

29. Mukai K, Gaudenzio N, Gupta S, et al. Assessing basophil activation by using flow cytometry and mass cytometry in blood stored 24 hours before analysis. J Allergy Clin Immunol. 2017;139(3):889-899 e811.

30. Sturm GJ, Kranzelbinder B, Sturm EM, Heinemann A, Groselj-Strele A, Aberer W. The basophil activation test in the diagnosis of allergy: technical issues and critical factors. Allergy.2009;64(9):1319-1326.

31. M P, A N, C M, et al. Building confidence in the basophil activation test: standardization and external quality assurance - an EAACI task force Allergy. 2020.

32. Patil SU, Calatroni A, Schneider M, et al. Data-driven programmatic approach to analysis of basophil activation tests. Cytometry B Clin Cytom. 2017.

33. Santos AF, Du Toit G, Douiri A, et al. Distinct parameters of the basophil activation test reflect the severity and threshold of allergic reactions to peanut. J Allergy Clin Immunol. 2015;135(1):179-186.

34. Erdmann SM, Sachs B, Kwiecien R, Moll-Slodowy S, Sauer I, Merk HF. The basophil activation test in wasp venom allergy: sensitivity, specificity and monitoring specific immunotherapy. Allergy.2004;59(10):1102-1109.

35. Johansson SG, Nopp A, van Hage M, et al. Passive IgE-sensitization by blood transfusion. Allergy. 2005;60(9):1192-1199.

36. Dahlen B, Nopp A, Johansson SG, Eduards M, Skedinger M, Adedoyin J. Basophil allergen threshold sensitivity, CD-sens, is a measure of allergen sensitivity in asthma. Clin Exp Allergy.2011;41(8):1091-1097. 
37. Nopp A, Cardell LO, Johansson SG. CD-sens can be a reliable and easy-to-use complement in the diagnosis of allergic rhinitis. Int Arch Allergy Immunol. 2013;161(1):87-90.

38. Glaumann S, Nopp A, Johansson SG, Rudengren M, Borres MP, Nilsson C. Basophil allergen threshold sensitivity, CD-sens, IgE-sensitization and DBPCFC in peanut-sensitized children. Allergy.2012;67(2):242247.

39. Nilsson N, Nilsson C, Hedlin G, Johansson SG, Borres MP, Nopp A. Combining analyses of basophil allergen threshold sensitivity, CD-sens, and IgE antibodies to hydrolyzed wheat, omega- 5 gliadin and timothy grass enhances the prediction of wheat challenge outcome. Int Arch Allergy Immunol. 2013;162(1):50-57.

40. Santos AF, Douiri A, Becares N, et al. Basophil activation test discriminates between allergy and tolerance in peanut-sensitized children. J Allergy Clin Immunol. 2014;134(3):645-652.

41. Nopp A, Cardell LO, Johansson SG, Oman H. CD-sens: a biological measure of immunological changes stimulated by ASIT. Allergy.2009;64(5):811-814.

42. Schmid JM, Wurtzen PA, Dahl R, Hoffmann HJ. Early improvement in basophil sensitivity predicts symptom relief with grass pollen immunotherapy. J Allergy Clin Immunol. 2014;134(3):741-744 e745.

43. Kosnik M, Silar M, Bajrovic N, Music E, Korosec P. High sensitivity of basophils predicts side-effects in venom immunotherapy.Allergy. 2005;60(11):1401-1406.

44. Lalek N, Kosnik M, Silar M, Korosec P. Immunoglobulin G-dependent changes in basophil allergen threshold sensitivity during birch pollen immunotherapy. Clin Exp Allergy. 2010;40(8):1186-1193.

45. Schmid JM, Wurtzen PA, Siddhuraj P, et al. Basophil sensitivity reflects long-term clinical outcome of subcutaneous immunotherapy in grass pollen-allergic patients. Allergy. 2020.

46. Nopp A, Johansson SG, Ankerst J, et al. Basophil allergen threshold sensitivity: a useful approach to anti-IgE treatment efficacy evaluation. Allergy. 2006;61(3):298-302.

47. Nopp A, Johansson SG, Ankerst J, Palmqvist M, Oman H. CD-sens and clinical changes during withdrawal of Xolair after 6 years of treatment.Allergy. 2007;62(10):1175-1181.

48. Nopp A, Johansson SG, Adedoyin J, Ankerst J, Palmqvist M, Oman H. After 6 years with Xolair; a 3-year withdrawal follow-up.Allergy. 2010;65(1):56-60.

49. Konradsen JR, Nordlund B, Nilsson OB, et al. High basophil allergen sensitivity (CD-sens) is associated with severe allergic asthma in children. Pediatr Allergy Immunol. 2012;23(4):376-384.

50. Brandstrom J, Nopp A, Johansson SG, et al. Basophil allergen threshold sensitivity and componentresolved diagnostics improve hazelnut allergy diagnosis. Clin Exp Allergy.2015;45(9):1412-1418.

51. Zidarn M, Kosnik M, Silar M, Grahek A, Korosec P. Rhinitis symptoms caused by grass pollen are associated with elevated basophile allergen sensitivity and a larger grass-specific immunoglobulin E fraction. Clin Exp Allergy. 2012;42(1):49-57.

52. Zidarn M, Kosnik M, Silar M, Bajrovic N, Korosec P. Sustained effect of grass pollen subcutaneous immunotherapy on suppression of allergen-specific basophil response; a real-life, nonrandomized controlled study. Allergy. 2015;70(5):547-555.

53. Patil SU, Shreffler WG. Immunology in the Clinic Review Series; focus on allergies: basophils as biomarkers for assessing immune modulation. Clin Exp Immunol. 2012;167(1):59-66.

54. MacGlashan DW, Jr. Releasability of human basophils: cellular sensitivity and maximal histamine release are independent variables.J Allergy Clin Immunol. 1993;91(2):605-615. 
55. MacGlashan DW, Jr. Relationship between spleen tyrosine kinase and phosphatidylinositol 5' phosphatase expression and secretion from human basophils in the general population. J Allergy Clin Immunol.2007;119(3):626-633.

56. Ishmael S, MacGlashan D, Jr. Early signal protein expression profiles in basophils: a population study. J Leukoc Biol.2009;86(2):313-325.

57. Santos AF, Shreffler WG. Road map for the clinical application of the basophil activation test in food allergy. Clin Exp Allergy.2017;47(9):1115-1124.

58. Hemmings O, Kwok M, McKendry R, Santos AF. Basophil Activation Test: Old and New Applications in Allergy. Curr Allergy Asthma Rep.2018;18(12):77.

59. Santos AF, Du Toit G, O ' Rourke C, et al. Identifying allergic children with severe adverse events during oral peanut challenges in the LEAP studies by assessing basophil activation. Allergy.2019;74(S106):73.

60. Santos AF, Lack G. Basophil activation test: food challenge in a test tube or specialist research tool? Clin Transl Allergy.2016;6:10.

61. Eberlein B, Krischan L, Darsow U, Ollert M, Ring J. Double positivity to bee and wasp venom: improved diagnostic procedure by recombinant allergen-based IgE testing and basophil activation test including data about cross-reactive carbohydrate determinants. J Allergy Clin Immunol. 2012;130(1):155-161.

62. Arzt L, Bokanovic D, Schrautzer C, et al. Immunological differences between insect venom-allergic patients with and without immunotherapy and asymptomatically sensitized subjects. Allergy.2018;73(6):12231231.

63. Wanich N, Nowak-Wegrzyn A, Sampson HA, Shreffler WG. Allergen-specific basophil suppression associated with clinical tolerance in patients with milk allergy. J Allergy Clin Immunol.2009;123(4):789-794 e720.

64. Berin MC, Grishin A, Masilamani M, et al. Egg-specific IgE and basophil activation but not egg-specific T-cell counts correlate with phenotypes of clinical egg allergy. J Allergy Clin Immunol.2018;142(1):149-158 e148.

65. Song Y, Wang J, Leung N, et al. Correlations between basophil activation, allergen-specific IgE with outcome and severity of oral food challenges. Ann Allergy Asthma Immunol. 2015;114(4):319-326.

66. Rubio A, Vivinus-Nebot M, Bourrier T, Saggio B, Albertini M, Bernard A. Benefit of the basophil activation test in deciding when to reintroduce cow's milk in allergic children. Allergy.2011;66(1):92-100.

67. Chinthrajah RS, Purington N, Andorf S, et al. Development of a tool predicting severity of allergic reaction during peanut challenge.Ann Allergy Asthma Immunol. 2018;121(1):69-76 e62.

68. Reier-Nilsen T, Michelsen MM, Lodrup Carlsen KC, et al. Predicting reactivity threshold in children with anaphylaxis to peanut. Clin Exp Allergy. 2018;48(4):415-423.

69. Burks AW, Jones SM, Wood RA, et al. Oral immunotherapy for treatment of egg allergy in children. $N$ Engl J Med. 2012;367(3):233-243.

70. Vickery BP, Scurlock AM, Kulis M, et al. Sustained unresponsiveness to peanut in subjects who have completed peanut oral immunotherapy.J Allergy Clin Immunol. 2014;133(2):468-475.

71. Shamji MH, Layhadi JA, Scadding GW, et al. Basophil expression of diamine oxidase: a novel biomarker of allergen immunotherapy response.J Allergy Clin Immunol. 2015;135(4):913-921 e919.

72. Thyagarajan A, Jones SM, Calatroni A, et al. Evidence of pathway-specific basophil anergy induced by peanut oral immunotherapy in peanut-allergic children. Clin Exp Allergy. 2012;42(8):1197-1205. 
73. Gorelik M, Narisety SD, Guerrerio AL, et al. Suppression of the immunologic response to peanut during immunotherapy is often transient.J Allergy Clin Immunol. 2015;135(5):1283-1292.

74. Hoffmann HJ, Valovirta E, Pfaar O, et al. Novel approaches and perspectives in allergen immunotherapy. Allergy.2017;72(7):1022-1034.

75. Santos AF, James LK, Kwok M, et al. Peanut oral immunotherapy induces blocking antibodies but does not change functional characteristics of peanut-specific IgE. J Allergy Clin Immunol.2019.

76. Patil SU, Steinbrecher J, Calatroni A, et al. Early decrease in basophil sensitivity to Ara h 2 precedes sustained unresponsiveness after peanut oral immunotherapy. J Allergy Clin Immunol.2019;144(5):1310-1319 e1314.

77. Santos AF, James LK, Bahnson HT, et al. IgG4 inhibits peanut-induced basophil and mast cell activation in peanut-tolerant children sensitized to peanut major allergens. J Allergy Clin Immunol.2015;135(5):12491256 .

78. McKendry RT, Kwok M, Hemmings O, James LK, AF S. Basophil and mast cell responses to food allergens in sensitised but tolerant patients are not mediated via the FcgRII and FcgRII receptors. Allergy.2019;74(S106):97.

79. MacGlashan DW, Jr., Saini SS. Syk expression and IgE-mediated histamine release in basophils as biomarkers for predicting the clinical efficacy of omalizumab. J Allergy Clin Immunol.2017;139(5):1680-1682 e1610.

80. MacGlashan DW, Jr., Savage JH, Wood RA, Saini SS. Suppression of the basophil response to allergen during treatment with omalizumab is dependent on 2 competing factors. J Allergy Clin Immunol.2012;130(5):1130-1135 e1135.

81. Ankerst J, Nopp A, Johansson SG, Adedoyin J, Oman H. Xolair is effective in allergics with a low serum IgE level. Int Arch Allergy Immunol. 2010;152(1):71-74.

82. Brandstrom J, Vetander M, Sundqvist AC, et al. Individually dosed omalizumab facilitates peanut oral immunotherapy in peanut allergic adolescents. Clin Exp Allergy. 2019;49(10):1328-1341.

83. Savage JH, Courneya JP, Sterba PM, Macglashan DW, Saini SS, Wood RA. Kinetics of mast cell, basophil, and oral food challenge responses in omalizumab-treated adults with peanut allergy. J Allergy Clin Immunol. 2012;130(5):1123-1129 e1122.

84. Macglashan DW, Jr., Saini SS. Omalizumab increases the intrinsic sensitivity of human basophils to IgE-mediated stimulation. J Allergy Clin Immunol. 2013;132(4):906-911 e901-904.

85. Eckman JA, Sterba PM, Kelly D, et al. Effects of omalizumab on basophil and mast cell responses using an intranasal cat allergen challenge. J Allergy Clin Immunol. 2010;125(4):889-895 e887.

86. Johansson SG, Nopp A, Oman H, et al. The size of the disease relevant IgE antibody fraction in relation to 'total-IgE' predicts the efficacy of anti-IgE (Xolair) treatment. Allergy.2009;64(10):1472-1477.

87. Patil SU, Calatroni A, Schneider M, et al. Data-driven programmatic approach to analysis of basophil activation tests. Cytometry B Clin Cytom. 2018;94(4):667-673.

88. Depince-Berger AE, Sidi-Yahya K, Jeraiby M, Lambert C. Basophil activation test: Implementation and standardization between systems and between instruments. Cytometry A. 2017;91(3):261-269.

89. Uyttebroek AP, Sabato V, Faber MA, et al. Basophil activation tests: time for a reconsideration. Expert Rev Clin Immunol.2014;10(10):1325-1335.

90. Ryherd M, Plassmeyer M, Alexander C, et al. Improved panels for clinical immune phenotyping: Utilization of the violet laser.Cytometry B Clin Cytom. 2018;94(5):671-679. 
91. Mukai K, Gaudenzio N, Gupta S, et al. Assessing basophil activation by using flow cytometry and mass cytometry in blood stored 24 hours before analysis. J Allergy Clin Immunol.2017;139(3):889-899.e811.

92. https://eur-lex.europa.eu/eli/reg/2017/746/oj. Accessed 6th July 2020.

93. Davis BH, Wood B, Oldaker T, Barnett D. Validation of cell-based fluorescence assays: practice guidelines from the ICSH and ICCS - part I - rationale and aims. Cytometry B Clin Cytom. 2013;84(5):282-285.

94. Davis BH, Dasgupta A, Kussick S, Han JY, Estrellado A. Validation of cell-based fluorescence assays: practice guidelines from the ICSH and ICCS - part II - preanalytical issues. Cytometry B Clin Cytom.2013;84(5):286-290.

95. Barnett D, Louzao R, Gambell P, De J, Oldaker T, Hanson CA. Validation of cell-based fluorescence assays: practice guidelines from the ICSH and ICCS - part IV - postanalytic considerations. Cytometry B Clin Cytom. 2013;84(5):309-314.

96. Tsai M, Mukai K, Chinthrajah RS, Nadeau KC, Galli SJ. Sustained successful peanut oral immunotherapy associated with low basophil activation and peanut-specific IgE. J Allergy Clin Immunol.2020;145(3):885896 e886.

97. Santos AF, Couto-Francisco N, Becares N, Kwok M, Bahnson HT, Lack G. A novel human mast cell activation test for peanut allergy. J Allergy Clin Immunol. 2018;142(2):689-691 e689.

98. Kleine-Tebbe J, Erdmann S, Knol EF, MacGlashan DW, Jr., Poulsen LK, Gibbs BF. Diagnostic tests based on human basophils: potentials, pitfalls and perspectives. Int Arch Allergy Immunol.2006;141(1):7990 .

99. de Weck AL, Sanz ML, Gamboa PM, et al. Diagnostic tests based on human basophils: more potentials and perspectives than pitfalls.Int Arch Allergy Immunol. 2008;146(3):177-189.

100. Wojtalewicz N, Goseberg S, Kabrodt K, Schellenberg I. Six years of INSTAND e. V. sIgE proficiency testing: An evaluation of in vitro allergy diagnostics. Allergo J Int. 2017;26(2):43-52.

101. Korosec P, Turner PJ, Silar M, et al. Basophils, high-affinity IgE receptors, and CCL2 in human anaphylaxis. J Allergy Clin Immunol.2017;140(3):750-758 e715.

102. Ocmant A, Mulier S, Hanssens L, et al. Basophil activation tests for the diagnosis of food allergy in children. Clin Exp Allergy.2009;39(8):1234-1245.

103. Eberlein B, Leon Suarez I, Darsow U, Rueff F, Behrendt H, Ring J. A new basophil activation test using CD63 and CCR3 in allergy to antibiotics. Clin Exp Allergy. 2010;40(3):411-418.

104. Leysen J, Bridts CH, De Clerck LS, Ebo DG. Rocuronium-induced anaphylaxis is probably not mitigated by sugammadex: evidence from an in vitro experiment. Anaesthesia. 2011;66(6):526-527.

105. Sturm GJ, Bohm E, Trummer M, Weiglhofer I, Heinemann A, Aberer W. The CD63 basophil activation test in Hymenoptera venom allergy: a prospective study. Allergy. 2004;59(10):1110-1117.

106. Gernez Y, Waters J, Mirkovic B, et al. Blood basophil activation is a reliable biomarker of allergic bronchopulmonary aspergillosis in cystic fibrosis. Eur Respir J. 2016;47(1):177-185. 